\title{
Sanitation and Hygiene of Darjeeling City: A Crisis for Women and Adolescent Girls
}

\author{
Kaberi Koner $^{\dagger}$
}

\section{Abstract}

By the end of the Millennium Development Goal's target year, 2015, India had been declared as a country, which has made moderate progress in terms of improvement in basic sanitation provision for all. Yet open defecation is still a regular practice of a significant proportion of the population in both urban and rural areas. The Indian government has been trying to address this problem for the last three decades through different programmes. However, though the effort is laudable, in reality, the countrywide situation is not so praiseworthy. Lack of sanitation provisions affects people in different ways with different intensities along the lines of class, gender, age, disability, and marginality. In Darjeeling city, due to lack of proper sanitation facilities, a significant portion of the population uses public toilets, which are less in number compared to the demand. People face a variety of difficulties and hurdles in using public toilets, and as a result, continue to practice open defecation during the night and early morning. Among the users, women and adolescent girls suffer more than the others. Moreover, in this city, a significant portion of the population faces acute water crisis during the dry months. This empirical study tries to explore the different ways through which women and adolescent girls are affected by the lack of safe sanitation facilities within the house premises. The article also argues that lack of sanitation provision should be considered as a matter of violence against women and adolescent girls because the situation makes them vulnerable to the risk of being violated or sexually abused.

Keywords: Sanitation, water, health, women's security, violence, Darjeeling, India

\footnotetext{
${ }^{\dagger}$ PhD Scholar, Department of Geography, The University of Burdwan, West Bengal, India Email: kaberikoner.geo@gmail.com

(C) 2018 Koner. This is an Open Access article distributed under the terms of the Creative Commons Attribution License (http://creativecommons.org/licenses/by/2.0), which permits unrestricted use, distribution, and reproduction in any medium, provided the original work is properly cited.
} 


\section{Introduction}

The water of sufficient quality and quantity, and hygienic sanitary practices are not only the pre-conditions to a healthy life but also the foundation for socio-economic growth (World Health Organisation [WHO] and The United Nations Children's Fund [UNICEF], 2006; Minh and Hung, 2011; Vedachalam and Riha, 2015). According to international organisations like the WHO and UNICEF (2010-Update), improved sanitation considers mainly the availability of physically closer facilities, short waiting time and safer excreta disposal. Primarily, the proper use of toilets and latrines are directly reliant on ample supply of water, though the issues related to drinking water have been receiving more attention than the necessity of water for sanitary purposes. Of course, both the problems of access to safe drinking water and adequate water for hygienic purposes are important.

The 2017 report of WHO and UNICEF unravels that 844 million people in the world still lack improved sources of drinking water and 2.3 billion people have no access to safe sanitation. India is no exception when it comes to these concerns. Regions, namely, South Asia, East Asia, and Sub-Saharan Africa suffer from lack of access to improved sanitation (O'Reilly, 2016: 51). According to WHO and UNICEF (2014, 2017), in India, around 48 per cent of the total population still practices open defecation (Bhattacharyya, 2014). Approximately, '600 million Indians defecate in open space; 130 million households fail to access drinking water, and no cities of India receive piped water and electricity supply 24X7' (Bhattacharyya, 2014: $2)$. In this context, Sulabh International, an India based civil society organisation has been working since 1970 amongst the disadvantaged population with building toilet facilities. Until now, Sulabh has constructed 1.5 million household toilets and 60 million government toilets. Besides, there are more than 8,500 Sulabh community toilet blocks in different parts of the country. Around 20 million people use Sulabh toilet complex daily, and the organisation has made 640 Indian towns scavenging free. ${ }^{1}$ Besides, many projects have been launched by the Indian government to improve basic infrastructure including water and sanitation over the past three decades, such as Integrated Development of Small and Medium Towns (IDSMT) in 1979-80; Integrated Low cost Sanitation Scheme (ILCS) in 1980; different projects under Jawaharlal Nehru National Urban Renewal Mission (JNNURM) in 2005; and the latest Clean India Campaign (Swachh Bharat Abhiyan), though the real picture has not yet changed to a satisfactory level. The Swachhta Status Report finds that in urban areas, 88.8 per cent households reported having sanitary toilets (The Hindu, October 2, 2016) however; the reality is far from the standards mentioned in the standard of Joint Monitoring Programme. Directed by Shree Narayan Singh and co-produced by Neeraj Pandey and Akshay Kumar, the Bollywood film, Toilet released on 11 August 2017 has unfolded the appalling issues of sanitation, especially in the rural areas of India, where women, children and elderly need to go out to the fields/open spaces to defecate. Using the narratives of a newly wedded bride, who refused to live in her in-law's house because of lack of toilet facilities, the central aim of the film, in conjunction with the Government of India's Swachh Bharat Abhiyan, is the complete elimination of open defecation. Nonetheless, the system of sanitation is still a massive threat to the people and the environment of the developing countries like India with its substantial demographic pressure. The booming urban population is exerting severe pressure on the existing overstretched infrastructure in the majority of the Indian cities (Thompson et al., 2000; Shaban and Sharma, 2007; Chaplin, 2011; Kumar, 2014). Over two decades ago, Kundu (1993) mentioned that the provision of housing and basic amenities to the urban poor is a big challenge for the developing world. Chaplin (2011) has rightly pointed out the two most

\footnotetext{
${ }^{1}$ Sulabh International Social Service Organisation, retrieved on 7 March 2018 from http://www.sulabhinternational.org/
} 
significant reasons behind the blurry situation of sanitation in the lower income countries are-first, is the colonial legacy of the state, that is, unequal access to sanitary provisions; unmanageable urban growth with proliferation of slums; and inadequate funding capacity of urban local governments. The second reason, as mentioned by Chaplin (2011) is about the nature of the postcolonial state, which is dominated by the interests of the middle class and becomes an instrument for using public funds to provide private goods. That means the allocation of financial resources and implementation of new projects are strongly influenced by the political considerations rather than the environmental or societal needs. Therefore, the state is not capable enough to serve the people equally in terms of the basic services. Kennedy-Walker (2015) said that it is always a tough task for the urban local bodies (ULBs) to extend basic services like water and sanitation to the poorest people who mainly live in the densely populated, low-income, informal settlements. Vedachalam and Riha (2015: 120) opined that in India, income, caste and gender mainly control the access to water and sanitation largely. Presently, in Indian social structure, the system of caste is a complex one, characterised by social stratification based on occupation, status in a hierarchy, and customary social interaction and exclusion (Bhattacharyya, 2009; 2013). 'People who belong to particular tiers of the caste system are often considered 'untouchable' and are systematically excluded from all aspects of society' (UN WATER, 2015: 11). Therefore, in case of access to water and sanitation, there are inequalities based on gender and level of income among the different communities of the society.

In the case of Darjeeling also, both water and sanitation services are limited in comparison to the demand, and undoubtedly, vulnerable groups in the scenario are the weaker sections, mainly the slum-dwellers. Amongst these slumdwellers, the hardest hit is the children, women and the elderly. Being the district headquarters, a favourite hill station and a reputed educational centre, the city has been experiencing continuous population growth for many years. Presently, the population pressure of Darjeeling is very high and is around 1, 18, 805 population (Census of India, 2011). In addition, Darjeeling, being one of the top-most international tourist destinations in India, receives a large number of tourists every year (Samanta and Koner, 2016), which falls under floating population. According to the capacity of infrastructural bases, the city is already overstretched. Urban Local Bodies (ULBs) cannot cope with the demand for fundamental needs like water and sanitation. In case of sanitary provisions, very few people have sanitised toilets and latrines. Others who have these facilities at their house premises have not adequately disinfected and maintained them, in case of the outlet. On the other hand, slum dwellers are entirely dependent on public toilets, which are very few (with only 109 public toilets in the whole city) compared to the demand. Like other Indian cities, the people of Darjeeling have also been facing discriminations in services provided in different areas of the city and among different economic classes. Joshi et al. (2011: 91) highlighted that the two critical aspects, which are linked with the topic of sanitation, are spatial (where one lives) and gender (complex identities, special needs and responsibilities).

Among the poor, women and adolescent girls disburse more to get the service than the other groups in terms of labour, time, health and money (Thara, 2017). Affected people feel a sense of insecurity and uncertainty daily for their regular sanitary needs (Gender Tool Box, 2015). The effects of water and sanitation crises on women and adolescent girls of the poor households are harsh due to everyday gendered chores and a few biological and cultural dilemmas. Therefore, questions of class and gender will be taken as the basis of discussion in the present study. This empirical study tries to explore the different ways through which women and adolescent girls are affected by the lack of sanitation facilities within the house premises. The article also argues that absence of sanitation provision should be considered as a matter of violence 
against women and adolescent girls because the situation pushes the affected women towards the risk of being violated or sexually abused.

The article begins with the methodological issues encountered while conducting the survey. It then gives a glimpse of the geographical location of the city and describes the condition of basic sanitation facilities available to the poor in the city. After that, in the following sections, it tries to explore the different kinds of problems faced by the women and adolescent girls. Finally, before concluding, it argues that the lack of sanitation facilities should be taken as the matter of injustice and violence against women and teenage girls. In the next section, the methodology is discussed.

\section{Methodology}

To understand the issues of poor sanitation and the predicaments faced by women, in-depth empirical research was carried out between 2015 and 2017. This is ethnographic research; mainly qualitative, though a few quantitative techniques are used during the interpretation of the data. Primary data has been collected from women and adolescent girls in the city through structured and semi-structured questionnaires and other qualitative techniques like focus group discussions, informal interviews and oral story. As the samples of this study are women and the topic of discussion is quite sensitive to them, qualitative techniques helped to acquire their real, lived experiences. Moreover, considering the sensitivity of the discussion, permission was taken from the interviewees. Some of them signed the questionnaires while others gave verbal authorisation but all of them had requested not to use their real names in the study. To maintain the dignity of the interviewees, all names used in the article are pseudonyms. The total samples covered in the survey are 140. Among the 140 interviewees, 120 are women (aged more than 21), and remaining 20 are adolescent girls (aged less than 21) from the selected slum areas of the city where the problem is acute.

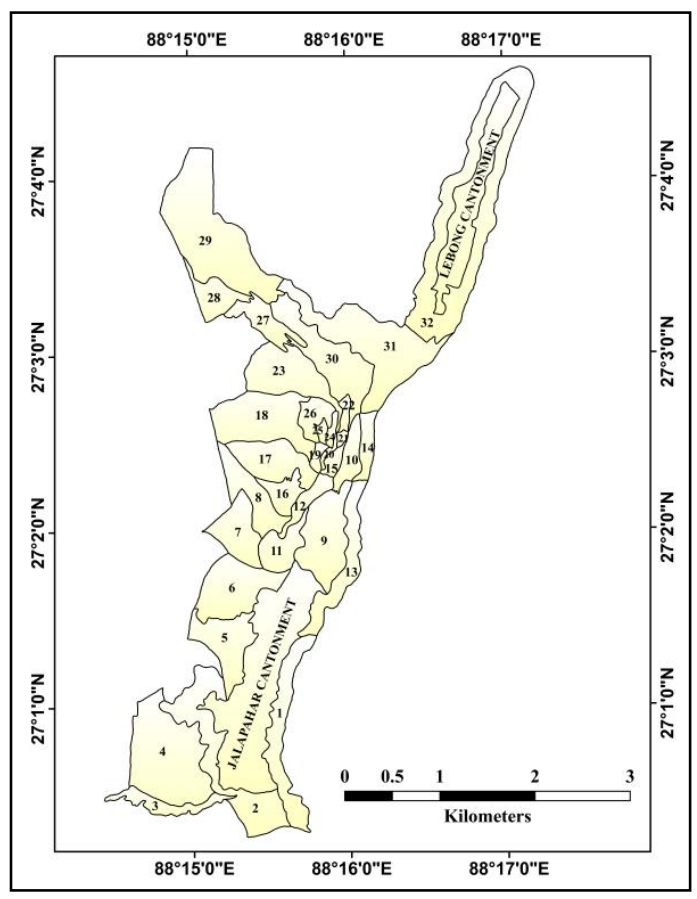

Figure1: Darjeeling Municipality Source: Prepared by the Author 


\section{The City: Location and Backdrop}

Darjeeling city is the administrative headquarter and the main urban centre of the district. Darjeeling Municipality (DM) is one of the oldest municipalities in the country. It was established in the year 1850 by the then British government. Now it has 32 wards and two cantonments (Jalapahar cantonment in the south and Lebong cantonment in the north) in the municipal area. The city is situated on the ' $Y$ ' shaped spurs elongated towards the northeast and northwest (two limbs) from the Ghoom range (Dash, 1947). The city is located at $27 \circ 3^{\prime} N$ \& 88 $16^{\prime} \mathrm{E}$, covering an area of 13.81 sq. Km (Figure 1). Currently, there are 37 notified slums with around 23 per cent of the slum population in the municipality.

\section{A Glance of the Sanitation Conditions of Darjeeling City}

Overall, the city of Darjeeling suffers from poor sanitation conditions. The city government does not properly manage both liquid and solid wastes. Here, around 22 per cent households have no latrine facilities in their house premises (Table 1). Slum dwellers are utterly dependent on public toilets, which are very few, compared to the demand. Out of the total slum population, which stands at 27,135, there are only 109 public toilets in different parts of the city (DM, 2012). In each toilet block, there are eight toilets, among which four are for males, and four are for females. According to the field observation, on an average 30 to 50 families are dependent on a public toilet block. As Wankhade (2015) mentioned that within a particular city, there are inequalities in access to services based on socioeconomic conditions and urban poor households are more likely to suffer from the unavailability of sanitation provisions. A similar picture can be seen in the Darjeeling city too.

Water is also not a readily available resource here. According to the field data, average water use per capita per day varies from 20 to 25 litres among the majority (77 per cent) of the surveyed households (Samanta and Koner, 2016). In the public toilets, there is no source of water. People have to carry water from their home. The rate of using toilet paper is higher among the public toilet users due to a shortage of water. Consequently, blockage of public latrines is a regular phenomenon, due to the lack of water and excessive use of toilet paper. Cleaning service provided by the municipality is not consistent and efficient. That is why the conditions of public toilets are not always usable and are unhygienic. Furthermore, open defecation is quite common here. Even now, five per cent households practice open excretion (Table 1). During monsoons and winter, people do not want to go far from their houses to defecate. Consequently, after sunset, open drains and open spaces become substitutes for the toilets. The deficiency in sanitation provisions directly helps to perpetuate the practice of open defecation in the city.

\section{Table 1: Sanitation Conditions in Darjeeling Municipality}

\begin{tabular}{|c|c|c|}
\hline \multicolumn{2}{|l|}{ Parameters } & Households \\
\hline \multicolumn{2}{|c|}{ Number of Households having Latrine facility within the House premises } & 78.6 \\
\hline \multicolumn{2}{|c|}{ Number of Households not having Latrine facility within the house premises } & 21.4 \\
\hline \multirow[t]{2}{*}{ Alternative source } & Public Latrine & 16 \\
\hline & Open & 5.4 \\
\hline \multirow{2}{*}{$\begin{array}{l}\text { Number of households having the bathing facility within the } \\
\text { house premises }\end{array}$} & Bathroom & 71.1 \\
\hline & Enclosure without & 4.4 \\
\hline \multirow{4}{*}{$\begin{array}{l}\text { No Bathroom } \\
\text { Wastewater outlet connected to }\end{array}$} & & 24.4 \\
\hline & Closed drainage & 26.5 \\
\hline & Open drainage & 62.7 \\
\hline & No drainage & 10.8 \\
\hline
\end{tabular}

Source: Household Amenities Data, Census of India, 2011. 
The users of the public latrines do not get enough time to use them properly. A long waiting time, like long queues during the time of water collection, is a ubiquitous feature at the public toilets in the mornings. Therefore, quarrels among the users are also a regular phenomenon. Besides, there is no electricity or separate doors in the public toilet blocks. Additionally, in the areas surrounding the toilet blocks, some anti-social activities like drinking liquor, gambling, etc. continuously takes place. Therefore, most users, mainly women and adolescent girls, do not want to go there after evening. Because of these factors, people try to avoid public toilets and use pay and use toilets when it is urgent, and where available.

Undoubtedly, in this situation, all the users face some difficulties, but the challenges faced by women and adolescent girls are far more due to various emblematic societal settings and biological needs. People residing in the slum areas take their bath and wash their clothes besides the roadside open drains. However, girls try to take their shower within their house premises. Not every house has sufficient space for making a bathroom, but they try to manage it within the very narrow space available there. Around 25 per cent households have no bathrooms within their premises (Table 1). Ethnographic observations revealed that people suffering from water shortage take a bath once every 10 to 15 days. Sometimes, it comes down to once a month, especially during the winter. Therefore, considering the data of Darjeeling municipality, Census of India (2011), and data collected from the field, it can be said that the sanitary practises of the people and sanitation condition of the city both are not hygienic and sustainable. In the following section, the problems faced by women and girls are discussed.

\section{Problems Faced by Women and Adolescent Girls}

It is almost a proven fact that the lack of sanitation provisions throughout the world has turned women and adolescent girls into the most vulnerable group among all the other groups in the society (WaterAid, 2012; Sommer et al., 2014; UN WATER, 2015; Nallari, 2015; O'Reilly, 2016). Many reports by the WHO, UNICEF, Gender Development Group of the World Bank, Asian Development Bank, UNWATER, UN-HABITAT (2006), UNHCR, WaterAid, among others, on the issues of water and sanitation crises, show that women and girls are the primary sufferers of these crises. Biologically and culturally, women are linked more closely with the issues of water and sanitation (Thara, 2017), and this susceptible state of affairs is present in almost all the developing countries of the world. As stated elsewhere, '[w]omen and girls experience sanitation need differently from men' (Sweetman and Medland, 2017: 154). Not only that, but children also suffer from the same, which indirectly exerts extra pressure on the women. That is why Satterthwaite et al. (2015) advised that children should be able to access the distant toilet facilities on their own, without the help of others. As mothers, women have to help their children access the sanitation provisions outside their house premises. Usually, women have the sole responsibility to collect and provide water to the other members of their family and to take care of their family's health and hygiene (UN HABITAT, 2006; WSP, 2010; GTB, 2015; Thara, 2017; Sweetman and Medland, 2017). To accomplish these responsibilities, women have to spend many hours a day, which they could have been used in other productive tasks (Thara, 2017). In this regard, Water Aid (2012) mentioned that availability of fresh water and sanitation helps the women in accessing the social and economic power that leads them to become a working woman or an agent of change within their community.

Where people do not have easy and safe access to sanitary provisions, they practice defecation in open spaces because they are compelled to do so. As already mentioned, open defecation and using public toilets with unhygienic conditions and feelings of insecurity have a negative impact on the social, mental and physical health of the dwellers, especially of women and adolescent girls. Nallari (2015: 73) also mentioned that 'absence of services puts 
inhabitants at risk, and in particular women and children in urban poor families, who are most affected physically, psychologically, socially and economically'. Therefore, not only does it affect their health and time, but also lack of sanitary provisions makes women and adolescent girls more vulnerable from or opens to threat.

Keeping in mind all these issues associated with the lack of proper sanitation facilities and women's daily hurdles, the following sections of the article explain how women and adolescent girls are affected in different ways by such a crisis in Darjeeling city. All these problems have been categorised into four sections: health problems, waste of time and money, the question of security, and the matter of dignity.

\section{Health Issues}

Health, a central issue of people's lives, does not only mean the absence of illness; instead, it includes physical, psychological and social wellbeing (Ibanez, 2011), though it does not get required attention in developmental discourses (Satterthwaite, 2011). People in developing countries suffer from many diseases and difficulties. Moreover, inadequate access to water and sanitation (GDG, 2002; Wankhade, 2015) makes these problems far worse. Diarrhoeal diseases, typhoid, trachoma, schistosomiasis, Hepatitis A, Hepatitis E, intestinal worms, child mortality, death during pregnancy, maternal health, menstrual hygiene, urinary infections, etc., are associated with the unavailability of safe sanitation provisions. These are the common findings of the studies conducted across several African and Asian countries by different international donor agencies like WHO, World Bank, UNICEF, UNESCO, UNDP, UN WATER, UN WOMEN, UNHCR, WaterAid, AquaFed, and so on. Kumar et al. (2011) showed that these diseases are also widespread in many urban areas of India, where water-sanitation is not sufficiently available for all.

Here, in Darjeeling city, the crises of water and sanitation mutually give birth to many diseases among which the most significant are: diarrhoeal diseases mainly during monsoon season (Table 2); skin diseases; urinary tract infections (UTI); reproductive tract infections; vaginal discharge and itching; intestinal worms; and Hepatitis A. These are observed mainly among those women and adolescent girls who are public toilet users and carry water from distant sources. These findings markedly signal these women and girls face a real crisis of these services in their everyday life and cannot maintain menstrual hygiene. Similar results have been shown by Nallari (2015) in her article where adolescent girls residing in the slums of Bengaluru suffer from heavy bleeding and pain in legs and back due to carrying water, and reproductive tract infections and urinary infections due to inadequate sanitation facilities.

In Darjeeling, the majority of the women and adolescent research participants replied that they try to control urination and to do so they drink less water throughout the day. They use roadside drains or open spaces to relieve themselves after sunset. More than 55 per cent research participants answered that 'we do not need to drink water in this cold climate. We take tea and coffee, and that works like water'. Besides, as water is also insufficient in the city, the majority of the women and adolescent girls use less amount of water in the toilet even when they bleed. They cannot maintain their menstrual hygiene properly. As they do not get sufficient water to clean themselves, they also take fewer baths, only twice or thrice in a month. They cannot even wash their day-today clothes regularly. According to Zerah (2000), if a person consumes less than 25 litres of water daily, it is not possible to maintain basic hygienic practices. Thompson et al. (2000) have also shown the connection between the quantity of water use and level of daily hygiene. Shortage of water deteriorates the quality of sanitary practices of women (Thara, 2017). That is why women have described feeling unclean and impure during the time of worship or prayer.

Not only in their houses, but adolescent girls also continue to face this crisis even in their schools, especially during menstruation. None 
of the government schools has proper sanitary facilities for girls. There is no system of water in the toilets and no arrangement for cleaning the toilets daily. Thus, these toilets remain unusable most of the time. All the adolescent research participants said that they do not want to go to school on the days when they bleed. If they go, they try not to use the toilets. In order to do so, they abstain from drinking water throughout the day. In this regard, Vedachalam and Riha (2015: 119) stated that provision of potable water and safe sanitation would affect not only the physical health but also stimulate the rate of school attendance and the scholastic ability of the students, particularly among the girls.

Doctors, mainly gynaecologists, general physicians and skin specialists from the District Hospital and DDMA Hospital (locally known as Planter's Hospital), were interviewed for this research. All of them gave their opinion, which due to the water-sanitation crises, the rate of diarrhoeal diseases is higher among the poor. This also becomes evident from the data accessed from the hospital. During the premonsoon to monsoon season (May to September), the numbers of diarrhoeal patients are higher than in the rest of the year (Table 2), and the number of diarrhoeal patients is also increasing over time (Table 3). According to the gynaecologists, women and adolescent girls mainly suffer from vaginal discharge syndrome, itching and UTI due to less consumption and less use of water in the toilets. Apart from this, due to uncleanliness in the public toilets, they also get affected by infectious diseases. Besides, different kinds of skin diseases are common among the poor women.

\section{Table 2: Number of Patients Suffering from Diarrhoea per Month in Darjeeling District Hospital} from 2010- 2016

\begin{tabular}{|c|c|c|c|c|c|c|c|c|c|c|c|c|}
\hline 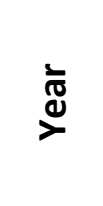 & 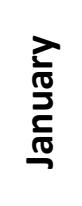 & $\begin{array}{l}\frac{2}{0} \\
\frac{\pi}{2} \\
\frac{2}{0} \\
\frac{0}{4}\end{array}$ & 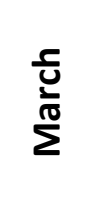 & 突 & $\stackrel{\mathbb{\pi}}{\Sigma}^{\lambda}$ & $\stackrel{\text { さ}}{\Xi}$ & $\frac{2}{2}$ & 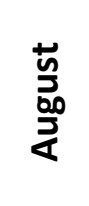 & 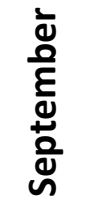 & $\begin{array}{l}\grave{\Xi} \\
\stackrel{0}{0} \\
\stackrel{U}{0}\end{array}$ & 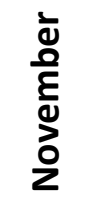 & 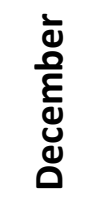 \\
\hline 2010 & 45 & 40 & 72 & 85 & 106 & 161 & 79 & 81 & 74 & 109 & 52 & 64 \\
\hline 2011 & 42 & 35 & 80 & 82 & 134 & 198 & 108 & 130 & 78 & 105 & 79 & 54 \\
\hline 2012 & 82 & 86 & 111 & 164 & 198 & 206 & 157 & 128 & 104 & 93 & 83 & 80 \\
\hline 2013 & 51 & 70 & 129 & 130 & 103 & 151 & 72 & 49 & 64 & 73 & 67 & 76 \\
\hline 2014 & 66 & 43 & 116 & 131 & 196 & 198 & 149 & 109 & 97 & 90 & 65 & 71 \\
\hline 2015 & 47 & 65 & 142 & 135 & 138 & 108 & 144 & 120 & 172 & 103 & 87 & 55 \\
\hline 2016 & 65 & 50 & 137 & 230 & 209 & 263 & 174 & 93 & 200 & 55 & 83 & 53 \\
\hline Total & 398 & 389 & 787 & 957 & 1084 & 1285 & 883 & 710 & 789 & 628 & 516 & 453 \\
\hline
\end{tabular}

Source: District Hospital, Darjeeling, May 2017.

\begin{tabular}{ll}
\multicolumn{2}{l}{ Table 3: } \\
\begin{tabular}{ll} 
Year & Total number of Diarrhoeal Patients from $\mathbf{2 0 1 0} \mathbf{- 2 0 1 6}$ \\
\hline 2010 & 968 \\
\hline 2011 & 1125 \\
\hline 2012 & 1492 \\
\hline 2013 & 1035 \\
\hline 2014 & 1331 \\
\hline 2015 & 1316 \\
\hline 2016 & 1612
\end{tabular}
\end{tabular}

Source: District Hospital, Darjeeling, May 2017 
The following two narratives in the form of case studies highlight the problems encountered by the participants on a daily basis.

\section{Case 1:}

A lady, named Mrs A. Khatun, age 67, who lives at Zakir Hussain Basti (Ward No-18) stated the difficulties she faces daily due to the lack of sanitation facilities in her house premises. The entire family uses public toilets and carry water from their home. Male members of her family do not face the same problems, which the female members face. She said that her three granddaughters, who are aged somewhere between 13 and 21, face severe challenges during their menstruation cycle. They cannot manage efficiently and feel shy. She said her granddaughters could not cope with the situation as they (Mrs. Khatun and her two widow daughters) do. All the female members of her family are suffering from UTI, itching and skin diseases. Other interviewed female members of the same community and the surrounding areas from Harizan Hatta also shared similar experiences.

\section{Case 2:}

A lady, named Mrs N. Rai, aged 51, who lives at Lower Jawahar Basti II (Ward no- 14) spoke about her and her neighbours' experiences regarding the lack of water and sanitation facilities. She said that she has been suffering from UTI, vaginal discharge and itching for the past 13 years. She also added that the doctors asked her not to use public toilets. The doctors suggested that she should use clean toilets and more water for sanitation purposes. However, she stated that she has no option.

In the city, research participants mainly from Aloobari Basti (Ward no-13), Jawahar Basti I and II (Ward no-14), Manglapuri and Sister Nivedita Gram (Ward no-17), Zakir Hussain Basti, Harizan Hatta, and Pragati Gram (Ward No-18), Shivagram and Jyoti Gram (Ward no23), Eden Compound (Ward no-26), Singtam Fatal (Ward no-28) and Bhutia Basti (Ward no31) stated that they have some health problems due to unhygienic sanitary practices. Even with these health issues, women and girls have to spend many hours every day just to use public toilets, which leave them with lesser time for other productive or aesthetic tasks. The disorganised sanitation system often causes the economic burden on the poor.

From the secondary data sources, it is also clear that in these areas, concentration of slum population (Figure 2), percentage of households having no latrines within their premises (Figure 3), percentage of households using public toilets (Figure 4), practice of open defecation (Figure 5), percentage of households having no bathrooms (Figure 6), percentage of open drains, etc., are all higher than the other areas of the municipality. Therefore, as the overall sanitation condition is not right in these areas, one can only imagine as to how people especially women and adolescent girls cope with their daily life.

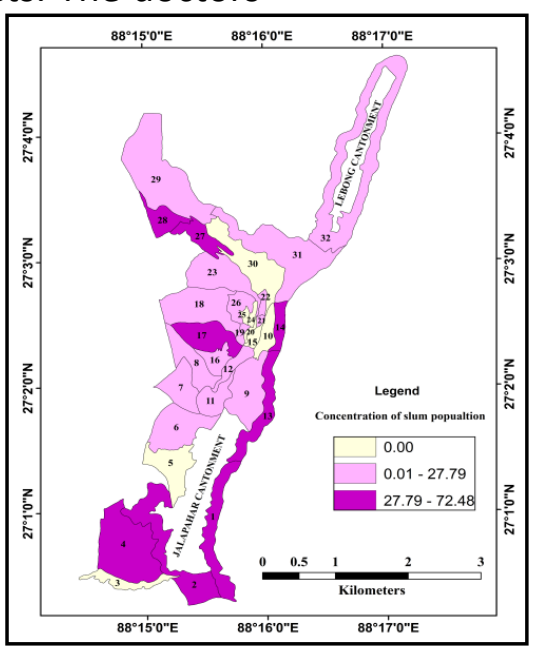

Figure 2: Concentration of Slum Population in Darjeeling Municipality Source: Prepared by the Author 


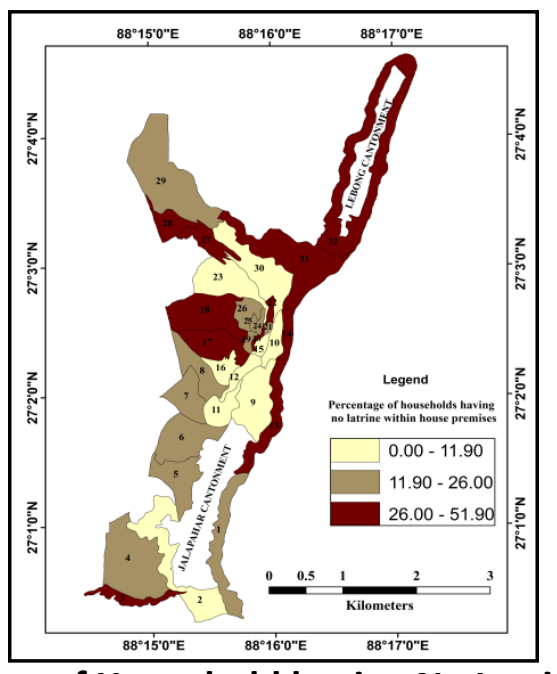

Figure 3: Percentage of Household having No Latrine within the House Premises Source: Prepared by the Author

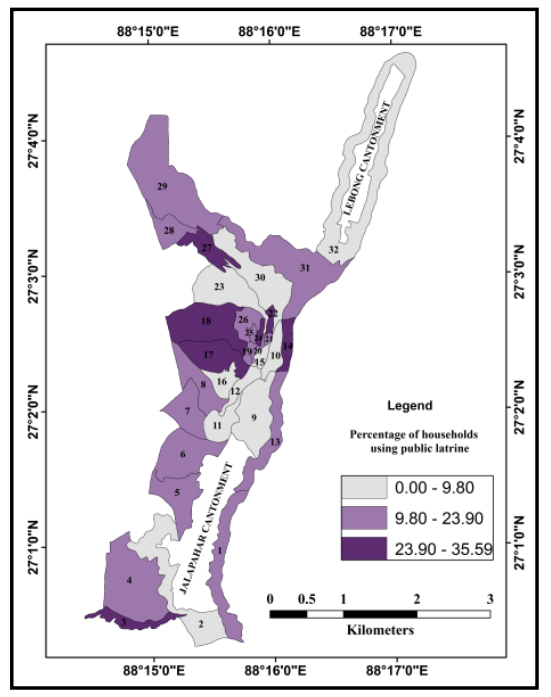

Figure 4: Percentage of Households using Public Latrine in the City

Source: Prepared by the Author

\section{Waste of Time and Money}

As the numbers of public toilets are less in comparison to the demand, users have to wait in a long queue. Long queues are common in the morning when people are in a hurry to get ready for their work. Women have extra responsibilities to make their children ready for school, as well. That is why they have to wait or spend more time at the public toilets for their children. It is observed that children do not want to go to use public toilets on their own. They want to go with their mother or elder siblings. Therefore, the women of those households, who are entirely dependent on public toilets, have to spend many hours in a day for this purpose. Furthermore, as mentioned earlier, the collection of water is also a time-consuming job for the women in Darjeeling city. Therefore, only for water and sanitation, women have to spend several hours in a day which could otherwise be used for taking rest or spending quality time for some more productive work, or for their children. Almost all the participants in the research agreed that they lose a lot of time because of this crisis (Samanta and Koner, 2016). Thara (2017) has shown similar findings in the case of poor women in slum areas of Bangalore.

Sometimes, due to time constraint, if the participants of the research go to the pay and use toilets, they have to pay for every single use, which is an extra economic burden for them (which are discussed below). However, if they want to manage their time properly, they 
have to use pay toilets even though these are not available in all parts of the city. Here, to understand the level of unaffordability for the poor households, this article tries to estimate the economic burden.

Considering the minimum cost for using the toilet once is ₹2, and the average family size is 5 , the total cost of using the toilet for a family is ₹10 in a day (for each person's single use in a day). It costs ₹300 per month for a household. Households having a monthly income between $₹ 5,000$ to 10,000 , have to spend 3 to 6 per cent of their total income for this purpose. However, using the toilet just once in a day cannot fulfil the absolute need of a person, and he or she may use it several times in a day. Moreover, for bathing, the rate is ₹5 in most of the pay toilets. If all five members take a bath once in a week, it costs ₹25 per week and ₹100 per month. Therefore, the percentage share of a household's budget for their sanitary purposes will be much higher. According to the calculation based on the filed data, this is 10 to 20 per cent of total income for the households having a monthly income between ₹5,000 to 10,000 . Therefore, it is unaffordable for the low-income households to get access to these services, because the affordability threshold should be between 2 to 6 per cent of total expenditure (WHO and UNICEF, 2017).

Thus, to reduce the expenditure for sanitation purposes or to avoid the difficulties of using public toilets, people are following unhealthy and unhygienic practices like open defecation. These are neither good for a healthy living nor the sustainability of the city's environment. Besides, open defecation always increases the risk of insecurity for women and the adolescent girls as exposed by Kulkarni et al. (2017). The women remain at high risk of facing sexual abuse, rape and other forms of violence against women (UN WATER, 2015). The next section deals with the question of security.

\section{Question of Security}

During the field survey, women and adolescent research participants stated that they do not go to the public toilets at night. There is no electric connection in the public toilets. Thus, it is tough to use those in the dark. Moreover, many anti-social activities like gambling by drunkards take place at or near the public toilet blocks after dusk. Therefore, women and adolescent girls feel scared to go to the toilet after evening. They use public toilets only during the daytime. Furthermore, as mentioned earlier, as most toilets do not have doors, the women and the adolescent girls do not feel comfortable in using those toilets, especially at night. Case 3 further reinforces these predicaments. In a similar context, Sommer et al. (2014: 108) argued that 'open-air sanitary facilities, insufficient bathing areas, and lack of lighting at night intensified the risks of sexual violence for those using the facilities'. Kulkarni et al. (2017) stated similar views in their research on women of Pune (Maharashtra) and Jaipur (Rajasthan).

\section{Case 3:}

Ms A. Tamag, a 17-year-old girl from Manglapuri (ward no-17), narrated that her friends use public toilets and sometimes even use open drains for defecation - all have faced different awkward situations. They had to face eve teasing by men, especially during menstruation. Therefore, whenever they go to defecate in the open at night, they feel a broad sense of fear and anxiety. That is why they try to go with their mothers.

According to UN-HABITAT (2006), practices like open defecation are not suitable for women's health and dignity. These also pose many risks when it comes to the matter of their security (Mara and Evans, 2011). Sommer et al. (2014: 114) seemingly suggested that 'there is a need to gather qualitative evidence on the feelings of safety when accessing water and sanitation services of people from different populations, along with their views on how well programming approaches have reduced vulnerabilities to violence and how services should be improved'. Almost all the research participants shared their vulnerable experiences of being molested or teased or even harassed during the time of defecation at public toilets or in the open. These unwanted 
episodes are humiliating for building the selfesteem of the women and adolescent girls.

\section{Matter of Dignity}

For women and adolescent girls, it is very shameful and undignified to use open drains as a toilet, particularly when they menstruate (Mara and Evans, 2011). In her research, Nallari (2015) has shared similar experiences of some adolescent girls, where it is evident that the girls feel embarrassed when they go to defecate in the open particularly when they bleed because men loiter around. Even though it is evident that they do not feel good, they do not have other options and are thus compelled to do so. Unsurprisingly, the majority of the research participants said that they first check that if there is anybody around them and then they sit to defecate. They also unravelled their sheer embarrassment about their practice of open defecation as a part of their everyday routine. Although for all women easy access to safe and hygienic toilets remains the key, for pregnant women, the situation becomes far worse to defecate in open spaces. In this regard, three pregnant women shared their bitter experiences. All three stated that they feel very shy when they go to defecate in the open or roadside drains due to their pregnancy.

UNICEF (2014) and the Ministry of Drinking Water and Sanitation (Government of India, 2015) have mentioned that menstrual hygiene management includes safe and hygienic items, knowledge and confidence on how to use them, adequate facilities for washing, and proper means for their disposal which would help in retaining both privacy and dignity for the women. In 2015, Satterthwaite et al. argued that 'women who are menstruating should have not only a way to wash but a place to put their waste safely and privately' (3). However, the research findings revealed that in the public toilets, there is no arrangement for disposing of sanitary napkins. Menstruating women and girls dispose of those openly in the toilets. The findings further unpacked that adolescent girls face the same problems in their schools too. Menstrual hygiene and privacy are not maintained anywhere in Darjeeling city. A woman has to live with the menstruation cycle for an average of 3,000 days in her life (UN WATER, 2015). WaterAid (2011) has opined that providing water, toilets and washrooms near the schools or in the home should be an integral part of a girl's education, which will help her to achieve her maximum potential. Women's menstrual hygiene receives very little attention amongst the state actors of Darjeeling city. Research participants, mainly from the slum areas of ward number 13, 14, 17, $18,28,31$ and 32 shared their repulsive experiences regarding feelings of insecurity and indignity due to lack of toilet facilities. In these areas, people do practice more open defecation (Figure 5), and the percentage of households without bathrooms are higher (Figure 6). Therefore, they are more susceptible to the risk of being humiliated.

\section{Lack of Sanitation: Injustice and Violence against Women}

Women and men have different roles and needs when it comes to the matter of watersanitation. Essentialities of sanitation lie at the core of the needs of women and adolescent girls (Nallari, 2015). 'Inadequate access to sanitation and hygiene disproportionally affect poor women and girls, as they are often faced with additional challenges related to menstrual hygiene, personal safety, sexual harassments and violence' (Gender Tool Box, 2015: 1; see also Mara and Evans, 2011; UN WATER, 2015; Kulkarni et al., 2017). Gender Development Group (2002) advocated years ago that if it is possible to ensure improved service, then the lives of women and girls will be benefitted.

When it comes to the matter of adolescence, undoubtedly, it is the most sensitive phase of the lives of the women when they pass through biological and psychological changes. In case of a traditional society like India, society makes some rules and regulations for the pubescent girls. 'Stigmatising adolescent girls and women through misguided beliefs and age-old cultural practices contribute to gender inequity and undermines basic rights' (Ministry of Drinking Water and Sanitation, Gol, 2015: 3). Nallari (2015: 75) stressed that 'adolescence in India is 
shaped by gender, caste, religion and class'. At this phase, if the adolescent girls do not get safe, secure and accessible sanitary provisions, it will harm their physical and mental state. UN WATER (2015) reported that due to traditional beliefs and practices, menstruation is considered as impure or unclean in many countries and does not get proper attention. The recently released (02 February 2018)
Indian film, Pad Man, which is based on the life of Mr Arunachalam Muruganantham, a social activist from the state of Tamil Nadu, who continues to promote menstrual hygiene through his invention of the low-cost sanitary napkin machine. The film is written and directed by R. Balki and is based on Twinkle Khanna's book entitled - The Legend of Lakshmi.

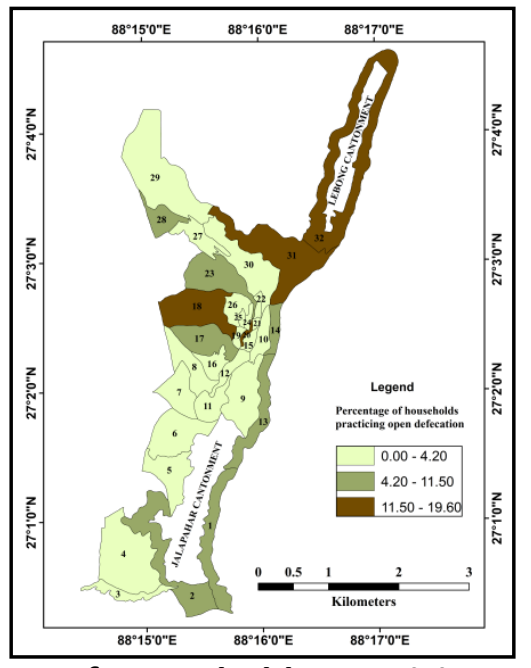

Figure 5: Percentage of Households Practicing Open Defecation within the City

Source: Prepared by the Author

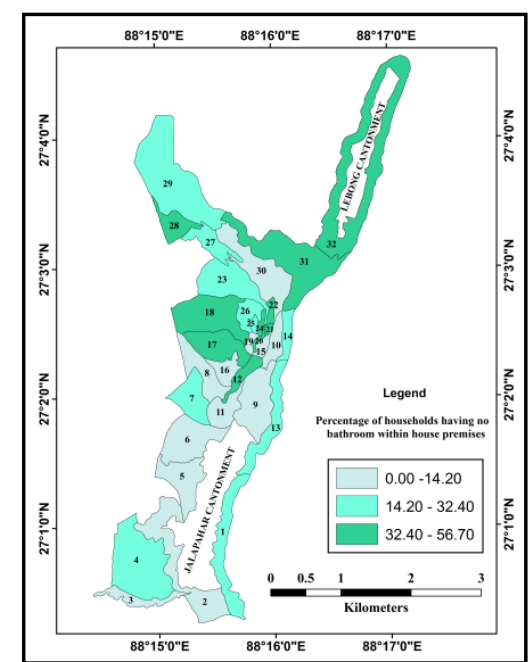

Figure 6: Percentage of Households Having No Bathroom Within The House Premises Source: Prepared by the Author

Notwithstanding, as already discussed earlier, Mara and Evans (2011) argued that the sanitation crisis pushes women and adolescent girls towards more danger. UN WATER (2015) advocated that everyone has the constitutional as well as human rights to get access to these services without any discrimination based on caste, sex, religion, socio-cultural or economic and political background, whereas most of the time, women and girls cannot enjoy the human rights linked to water and sanitation. Strong linkages are there in between the level of access to water, sanitation, hygiene, and gender equality (GTB, 2015; Kulkarni et al., 2017). Scholars like Sommer et al. (2014: 105), Kulkarni et al. (2017: 168), and others have stated that lack of access to toilets or poorly designed and maintained services of water, 
sanitation and hygiene (WASH) can increase the vulnerability to violence. Sommer et al. (2014) argued that long-distance travel for collecting water or long periods of waiting until the evening to defecate in the dark increases the vulnerability to violence, whereas Kulkarni et al. (2017) opined that risk of rape, assault, and other kinds of physical harassment increases in the overcrowded, impoverished urban areas where sanitation facilities are insufficient. In this regard, Nallari (2015: 73) also pointed out 'how lack of access to safe and well-maintained sanitation facilities can contribute to many deprivations (education, free time, privacy, independent mobility) and risk (sexual harassment, assault and health risk), which can be a structural pathway for cyclical gender-based disempowerment and injustice'. In this regard GTB's (2015:1-2) comments:

...without access to latrines, many women and girls become 'prisoners of daylight', using only the night as privacy. Night-time trips to fields or roadsides expose them to risk of physical attack and sexual violence. To ignore their natural bodily functions out of fear causes discomfort but also increases the risk of being affected by health problems such as urinary tract infections, chronic constipation and mental stress.

Taking all these findings on board, the research questions why uncertainties or improper access to water-sanitation is not considered as a structured form of injustice and violence against women. Limited or no access to sanitation services are the real injustice and create opportunities for violence and sexual assault against women.

\section{Conclusion}

This research set out to examine the everyday sanitation problems faced by women of Darjeeling city. Therefore, to some extent, it can be argued that life has become very tough for the affected women and adolescent girls, and the lack of adequate water and sanitation hinders their ability to survive confidently in the city. The security and dignity of the affected women and adolescent girls have been violated, and they are humiliated indirectly by the inadequate and inefficient services of local governments. Lack of funds, legal issues, and political unwillingness are the probable reasons behind the messy sanitary situation of Darjeeling. No special measures and policies have been implemented to give better services to the poor and especially the women and adolescent girls. Nallari (2015: 74) argued that '[a]ccess to municipal services in Indian cities [are] manipulated by the middle and upper classes of the society'.

Considering the magnitude of the problem, a few small measures are suggested which can change the present situation and give some comfort to the users. These are-electricity in the toilets; doors in front of each toilet; the arrangement for supply of water in these toilet blocks; regular cleaning; special disposal boxes in the ladies' toilets; and an active administration to control the anti-social activities near the public toilet blocks. A few small gender-sensitive plans using the gender lens will meet the needs of women and adolescent girls (Water and Sanitation Program, 2010), and inevitably increase their confidence and minimise the chances of sexual harassment. This will help them to maintain their menstrual hygiene and dignity largely.

Besides, the municipality can take an initiative in which users may be given the responsibility of maintenance by forming a committee. WaterAid (2011) suggested that except for the most basic system such as open water sources and open defecation, all services incur some repairing and maintenance costs. Therefore, both the municipality and users can then take part in case of financial and managerial support.

If these measures are taken into consideration, the problem can inevitably be reduced. That will surely help in the development of the city as the improved water-sanitation system has multiple positive effects, and can reduce the degree of poverty, physical labour, diseases, gender discrimination, and other social 
problems (AquaFed, 2007; and WaterAid, 2012). Therefore, "to deliver 'development' in [the] real sense of the term, the component 'justice' must not only be added but also embellished to the notion of 'development'" (Bhattacharyya, 2014: 1).

\section{References}

AquaFed.(2007). Water and sanitation for women. Retrieved from www.aquafed.org/pdf/gender_aquafed_e n_pc_2007-03-08.pdf

Bhattacharyya, R. (2014). Good governance and development mandate. Space and Culture, India.2 (1): 1-3, https://doi.org/10.20896/saci.v2i1.65

Bhattacharyya, R. (2013). Are we empowered? Stories of young Indian working women, Saarbrücken, Germany: Lap Lambert Academic Publishing, (ISBN: 978-3-65920580-4)

Bhattacharyya, R. (2009). Examining the changing status and role of middle class Assamese women: lessons from the lives of university students. PhD Thesis, University of Newcastle, United Kingdom. Retrieved on 28 February 2018 from, https://theses.ncl.ac.uk/dspace/handle/10 $443 / 303$

Census of India.(2011). Household amenities data. New Delhi: GOI.

Chaplin, S. E. (2011). The politics of sanitation in India. New Delhi: Orient Blackswan Private Limited.

Darjeeling Municipality.(2012). Project report of conservancy department.

Dash, A. J. (1947).Bengal district gazetteer. Alipore: Bengal government press.

Gender Development Group. (2002). Water, sanitation and gender equity. Washington DC: World Bank. Retrieved from http://siteresources.worldbank.org/INTGE NDER/Resources/watersanitation.pdf.

Gender Tool Box (Brief). (2015). Women, water, sanitation and hygiene. Sida.1-5.
Ibanez, E. L.I. (2011). Municipality, space and the social determinants of health. Environment and Urbanization 23(1): 113117.

Joshi, D., Fawcett, B., and Mannan, F. (2011).Health, hygiene and appropriate sanitation: experiences and perceptions of the urban poor. Environment and Urbanization 23(1): 91-111.

Kennedy-Walker, R., Amezaga, J. M. and Paterson, C. A. (2015).The role of power, politics and history in achieving sanitation service provision in informal urban environments: a case study of Lusaka, Zambia. Environment and Urbanization 27(2): 489-504.

Kulkarni, S., O’Reilly, K., \& Bhat, S. 2017. No relief: lived experiences of inadequate sanitation access of poor urban women in India. Gender and Development 25(2): 167-183.

Kumar, D.M. (2014). Thirsty cities: How Indian cities can meet their water needs. New Delhi: Oxford University Press.

Kumar, S. G., Kar, S. S, Jain, A. (2011). Health and environmental sanitation in India: Issues for prioritizing control strategies. Indian Journal of Occupational Environmental Medicine 15 (3): 93-96. Retrieved from http://www.ijoem.com/text.asp?201 1/15/3/93/93196

Kundu, A. (1993). In the name of the urban poor: Access to basic amenities. New Delhi: SAGE.

Mara, D. and Evans, B. (2011).Sanitation and water supply in low income countries. Ventus Publishing ApS

Minh, H. V. and Hung, N. V. (2011).Economic aspects of sanitation in developing countries. Environmental Health Insights 5: 63-70.

Ministry of drinking water and sanitation, Government of India. (2015). Menstrual hygiene management: National Guidelines. New Delhi: GOI. 
Nallari, A. (2015). "All we want are toilets inside our homes!" The critical role of sanitation in the lives of urban poor adolescent girls in Bengaluru, India. Environment and Urbanization 27(1): 73-88.

O’Reilly, K. (2016). Surviving as an unequal community: WASH for those on the margins, in P. Jackson et al. (eds), Eating, Drinking: Surviving. (pp. 51-56). Springer Briefs in Global Understanding.

Samanta, G. \&Koner, K. (2016).Urban political ecology of water in Darjeeling, India. South Asian Water Studies 5 (3): 42-57.

Satterthwaite, D. (Ed.). (2011). Editorial: Why is urban health so poor even in many successful cities? Environment and Urbanisation 23(1): 5-11.

Satterthwaite, D., Mitlin, D., and Bartlett, S. (eds). (2015). Editorial: Is it possible to reach low-income urban dwellers with good-quality sanitation? Environment and Urbanisation 27(1): 3-18.

Shaban, A. and Sharma, R. N. (2007).Water consumption pattern in domestic households in major cities. Economic and Political Weekly 42(23): 2190-2197.

Sommer, M., Ferron, S., Cavill, S. and House, S. (2014).Violence, gender and WASH: spurring action on a complex, underdocumented and sensitive topic. Environment and Urbanization 27(1): 105116.

Sweetman, C. \&Medland, L. (2017) Introduction: Gender and water, sanitation and hygiene. Gender and Development 25(2): 153-166.

Thara, K. (2017). In troubled waters: Water commodification, law, gender, and poverty in Bangalore. Gender and Development 25(2): 253-268.

The Hindu. (October 02, 2016). What numbers tell us about open defecation in India. Retrieved from http://www.thehindu.com/data/Whatnumbers-tell-us-about-Open-Defecationin-India/article15422326.ece
Thompson, J., Porrars, Ina. T., Wood, E., Tumwine, J. K., Mujwahuzi, M. R., KatuiKatua, M. and Johnstone, N. (2000).Waiting at the tap: Changes in urban water use in east Africa over three decades. Environment and Urbanisation 12(2): 37-52.

UN-HABITAT. (2006). Framework for gender mainstreaming: Water and sanitation for cities. pp. 1-31. Retrieved from http://www.unhabitat.org/downloads/doc s/GenderMainsteamReport.pdf

UNICEF. (2014). The rights to water and sanitation. Current issues, No 3. Retrieved from

https://www.unicef.org/media/files/Curre nt_Issues_Paper-

_The_Rights_to_Safe_Water_and_Sanitati on.pdf

UN WATER.(2015). Eliminating discrimination and inequalities in access to water and sanitation. Geneva, Switzerland: UN-Water Technical Advisory Unit. Retrieved from http://www.ohchr.org/Documents/Issues/ Water/DiscriminationPolicy.pdf

Vedachalam, S. and Riha, S. J. (2015).Who's the cleanest of them all? Sanitation scores in Indian cities. Environment and Urbanization 27(1): 117-136.

Wankhade, K. (2015). Urban sanitation in India: Key shifts in the national policy frame. Environment and Urbanization 27(2): 555572.

WaterAid.(2011). Sustainability framework. Retrieved from www.wateraid.org/publications

WaterAid. (2012). Empowering women and girls: How water, sanitation and hygiene deliver gender equality. pp 1-17. Ethiopia: WaterAid Eastern Africa Region.

Water and Sanitation Program (WSP). (2010). Gender in water and sanitation. Working paper. Nairobi, Kenya: World Bank. pp. 137.

World Health Organization (WHO) and United Nations Children's Fund (UNICEF). (2006). 
Meeting the MDG Drinking Water and Sanitation Target: The Urban and Rural Challenge of the Decade. Geneva, Switzerland: WHO.

World Health Organization (WHO) and United Nations Children's Fund UNICEF: (2010) Progress on sanitation and drinking water2010 update. Geneva: World Health Organization.

World Health Organization (WHO) and United Nations Children's Fund (UNICEF).(2014). Progress on Drinking Water and Sanitation - 2014 Update, Joint Monitoring Programme. Geneva, Switzerland: WHO. Available at http://www.who.int/water_sanitation_hea Ith/publications/2014/jmp-rport/en

World Health Organisation (WHO) and United Nations Children's Fund (UNICEF).(2017).
Progress on drinking water, sanitation and hygiene (Update and SDG baseline).Geneva, Switzerland: WHO.

Zerah, M.H. (2000). Water: Unreliable supply in Delhi.New Delhi: Manohar Publishers.

\section{Acknowledgement}

The article is developed from the author's ongoing PhD research. The author acknowledges the kind help received from Professor Gopa Samanta, Department of Geography, The University of Burdwan in terms of valuable suggestions and critical comments on the draft article. The author expresses her sincere gratitude to the anonymous reviewers for their thoughtful critical comments in improving the article. Finally, author gives heartfelt thanks to the research participants for their kind cooperation without which the study would not be in the present shape. 